\title{
ECLESIÁSTICOS ENTRE LOS PENSIONADOS Y CIENTÍFICOS DE LA JUNTA PARA AMPLIACIÓN DE ESTUDIOS
}

POR

\author{
Justo Formentín IbáÑez y M.* José ViLlegas SANZ \\ Centro de Estudios Históricos - CSIC. Madrid
}

\section{RESUMEN}

Muchos autores han señalado que la Junta para Ampliación de Estudios, sobre todo en sus primeros años, discriminó a los sectores más tradicionales ideológicamente y sobre todo a los hombres de Iglesia. Este trabajo da a conocer los clérigos cuyo primer apellido comienza por la letra «A» que solicitaron una pensión de la Junta y hace un análisis detallado de aquellos a los que les fue concedida, así como de Miguel Asín Palacios, director desde 1910 de una de las secciones del Centro de Estudios Históricos, para concluir que, aunque se trate de una pequeña muestra y en espera de posteriores estudios, no hubo tal discriminación.

\section{Abstract}

Many writers have remarked that the JAE, specially in its first years, usually decided against the most ideologically traditional sectors and mainly against the clergymen. This article presents the clergymen, whose family name begins with an «A», that applied for a grant from the «Junta» and details those who received it. The article also studies Miguel Asín Palacios, president since 1910 of one section of the Historical Studies Centre. Finally the article shows that a discrimination didn't exist, even though we should await further studies to confirm this conclusion.

El 15 de enero de 1907 se fundaba la Junta para Ampliación de Estudios e Investigaciones Científicas (en adelante Junta o JAE), gracias a la tenacidad e iniciativa de hombres con talante reformista como Giner de los Ríos, Cossío o Castillejo. Los tres pertenecían a la Institución Libre de Enseñanza (en ade- 
lante $\mathrm{LE}$ ) y los tres influyeron notablemente en la JAE, aunque estos organismos nada tenían que ver el uno con el otro. Sobre este punto escribe Alfonso Ruiz Miguel:

«La Institución Libre de Enseñanza y la Junta son dos instituciones muy diferentes en varios aspectos: crecen en tiempos y circunstancias distintos, divididos idealmente por la conciencia del desastre nacional que se ha cifrado en la fecha de 1898; la ILE era una institución privada y la JAE un organismo público; la ILE se dedicó directamente a la enseñanza primaria y secundaria (formación de alumnos) y la JAE fomentó indirectamente la mejora de toda la enseñanza, con particular atención a la universitaria (formación de profesores); la labor de la ILE fue, al menos cuantitativamente, menos importante que la de la JAE...»1

Solo una cosa tenían en común: sus fundadores. Por ello ambas instituciones estaban imbuidas del mismo espíritu, de una común afinidad cultural e ideológica. No resultaba por ello extraño el grupo mayoritario de institucionistas que se encontraban entre los 21 vocales integrantes de la primera Junta para Ampliación de Estudios ${ }^{2}$, como puede observarse al revisar cada una de sus biografías. De entre ellos solamente un tercio no tenía vinculación alguna con la ILE.

Los vocales de la Junta se renovaban cada cierto tiempo. La mitad de los mismo dimitía y dejaba paso a otros nuevos que eran propuestos al Ministerio por la Junta saliente, por lo que es muy posible, que en los primeros años de su andadura se mantuviese esta mayoría institucionista. Del modo indicado se procedió siempre en la designación de los vocales de la JAE, excepción sea hecha de los años comprendidos entre 1926 y 1930, durante la Dictadura de Primo de Rivera, en los que de acuerdo con el Real decreto de 21 de mayo del primer año citado se introdujeron cambios en la composición de la Junta y se renovaron la mitad de sus vocales, que fueron nombrados directamente por el Ministro de Instrucción Pública.

Sin entrar ahora en juicios de valor sobre las intenciones de quienes promovieron la creación y el funcionamiento de la Junta, lo cierto es que ésta elegia a sus miembros (no solo vocales, directores de centros, profesores, etc.) entre hombres de gran prestigio intelectual y a pesar de que los primeros vocales fuesen mayoritariamente institucionistas, las más diversas tendencias científicas, políticas, sociales y religiosas estuvieron representadas y siempre supeditadas al prestigio intelectual de sus representantes. La disparidad ideo-

\footnotetext{
1 RUZ MiGUEL, Alfonso, «La Junta para Ampliación de Estudios», en Historia - 16, V, 49, mayo 1980 , p. 86.

2 GÓMEZ MOLLEDA, MP Dolores, Los reformadores de la España contemporanea, Madrid, CSIC, 1966, p. 458, nota 1.
} 
lógica de los vocales, no impidió que éstos discutiesen libremente sus opiniones con sumo respeto y después tomasen sus acuerdos por unanimidad. A las sesiones de la Junta plena solían faltar parte de sus vocales y en algunos casos las ausencias fueron bastante considerables. Menéndez Pelayo, por ejemplo, sólo acudió a una de aquellas reuniones durante los cinco años que perteneció a la JAE. En cambio hubo otros vocales que fueron muy asiduos en su asistencia a los plenos, en los que entre otros muchos asuntos se deliberaban y se decidian las concesiones de las solicitudes de pensión.

Además de los vocales de la Junta, los ponentes tenían mucha importancia en la selección de los pensionados, pues ellos daban su dictamen positivo o negativo sobre las instancias presentadas, dictamen que a medida que aumentaba el número de solicitudes, tuvo cada vez más peso específico en la adjudicación de las pensiones.

Para dar un juicio justo sobre la parcialidad o imparcialidad de la Junta en la selección de pensionados, de acuerdo con lo que dice Gómez Molleda, habría que consultar:

\footnotetext{
«...la correspondencia y el papeleo burocrático entre su Secretaría -Castillejo, Bemaldo de Quiros, Gonzalo de la Espada- enviando las peticiones de los pensionados a los respectivos informadores y las contestaciones de éstos, antes de las propuestas definitivas. Habría también que ver quiénes pedían las pensiones y a quienes eran denegadas y por quién, y si estas denegaciones llevaban informe o se liquidaban sin informe previo»3.
}

Respecto al peso decisivo que tenían los ponentes en la aceptación o denegación de las pensiones solicitadas, ponemos a guisa de ejemplo dos casos antagónicos en el tema que nos ocupa. El primero se refiere al dominico Luis Alonso Getino, solicitante de una consideración de pensionado para visitar varias naciones de América. Domingo Barnés escribe a Castillejo recomendándolo en los siguientes términos:

«Ya sabe lo simpático, lo culto y lo comprensivo que es este intelectual de la Orden. Está deseoso de la consideración y suplicando que, de ser posible, se tramite con la mayor rapidez...4.

Unos días después, el 17 de octubre de 1922, Ramón Menéndez Pidal, que había sido designado ponente, envió a la Junta un informe muy favorable sobre el P. Getino expresando que debía concedérsele la solicitud y que urgía por el plazo de su viaje. Al día siguiente se le firmaba la consideración de pensión.

3 GOMEZ MOLLEDA, MP Dolores, op. cit. p. 459.

4 Archivo JAE, caja 1799: Carta de Domingo Barnés a Castillejo, octubre de 1922. 
El segundo caso corresponde a una solicitud de pensión, cuya materia de estudio versaba sobre «Política religiosa de Carlos I en los Países Bajos». En esta ocasión, el ponente Tomás Navarro Tomás denegó la petición por tratarse de un tema religioso. Así consta en la documentación pertinente.

Cabe preguntarse si la JAE, dada la ideología de muchos de sus componentes, favoreció claramente a las personas relacionadas con la Institución Libre de Enseñanza o no; y si dicho organismo consideró justamente los méritos académicos de los elementos conservadores o católicos, que pedían subvenciones para salir al extranjero.

En la contestación a estas preguntas se basa la solución del debate sobre la parcialidad o imparcialidad de la JAE. No cabe duda que ésta siempre manifestó su intención y espíritu de neutralidad:

«De cómo ha cumplido la Junta con aquel primer deber de la imparcialidad, pueden dar fe la igualdad con que han sido considerados, ante el criterio único de la competencia y la vocación, los representantes de las más opuestas direcciones; la lucha sostenida para colocar esta obra fuera del radio de los intereses de secta o partido.... $\%^{5}$.

Por su parte Castillejo, secretario y alma de la JAE, era hombre de espíritu tolerante y respetuoso que en numerosas ocasiones expres6 su afán de mantener a la Junta al margen de la política y de las ideologías. Así habla de él Salvador Madariaga:

«Era en una palabra, un español objetivo. Rara avis. Jamás le preocuṕ que tal o cual joven de los universitarios que mandaba al extranjero, fuera de tal o cual partido, opinión, religión o sociedad pública o secreta» 6 .

Estas no dejan de ser opiniones que hacen necesarios estudios pormenorizados, pero en general, parece recta la intención de la Junta al aplicar criterios objetivos en la concesión de pensiones.

Algunos autores han señalado que en los primeros años los institucionistas se vieron favorecidos frente a solicitantes más conservadores o católicos o incluso más concretamente clérigos. Subirá ya en 1924 se mostraba contrario a esta teoria: «entre sus pensionados en el extranjero, entre sus becarios de la Escuela Española en Roma y entre sus profesores del Centro de Estudios Históricos de ella dependientes, había personas cuyos hábitos talares no fueron

\footnotetext{
s JAE, Memoria correspondiente a los afios 1910 y 1911, Madrid, JAE, 1912, p. 8.
}

6 Madariaga, Salvador, Españoles de mi tiempo, Barcelona, Planeta, 1981, p. 186. 
6́bice para que su positivo valer quedase reconocido y premiado» ${ }^{7}$. Y el canónigo de Oviedo Manuel Arboleya, 10 años antes, rebatía la acusación de sectarismo que entonces se hacía a la Junta en un artículo publicado en $A B C$ el 5 de marzo de 1914:

«He oido decir muchas veces, y lo he leído, que esa Junta no concede las tales pensiones más que a los radicales. Bien; pues yo me creo en el caso de afirmar que a mí, clerical y sacerdote, se me concedió la pensión solicitada sin que me costara más trabajo que eso: solicitarla; y añado que otro tanto pueden decir algunos sacerdotes más que se hallan en mi caso. Esta es la verdad, y porque lo es y acaso convenga decirla, aquí la expongo».

Y añade en otro artículo publicado en El Debate el 18 de ese mismo mes:

«,...esa Junta, donde hay, dicho sea de paso, excelentísimos católicos,nos ha concedido con la mayor facilidad sendas pensiones a varios eclesiásticos que las solicitamos; citaré conmigo a Madrigal, Morán, Amor, ete»9

No parece cierto que los clérigos fuesen excluidos de los beneficios de la Junta para Ampliación de Estudios por el solo hecho de ser clérigos. En este punto centraremos nuestro artículo, realizando un análisis biográfico de aquellos clérigos cuyo primer apellido comienza por la letra «A», que sí obtuvieron pensión de la Junta. No es este un estudio total pero, al menos, resulta en sí una muestra que destruye algunos tópicos sobre el comportamiento de la Junta con respecto a la concesión de pensiones a elementos conservadores. Pendientes quedan posteriores estudios que analicen en su totalidad las solicitudes de clérigos y las concesiones obtenidas; así como que analicen también, atendiendo a la primera cuestión planteada, la proporción de institucionistas que obtenían pensión, si se desviaba de la media, si se dio una proporción más alta de éstos en los primeros años de la Junta, como algunos aseguran, etc.

No se ha realizado ningún estudio sobre los eclesiásticos concretos que recibieron subvención de la Junta. Según los datos registrados en el inédito estudio sobre los distintos aspectos de la JAE dirigido por Francisco J. Laporta ${ }^{10}$, las solicitudes de pensión de clérigos fueron 95 y las concesiones 16 , lo cual

\footnotetext{
7 Subira, José, Una gran obra de cultura patria: La Junta para Ampliación de Estudios, Madrid, Imp. de «Alrededor del mundo», 1924, p. 62.

Citado en Subirá, José, op. cit. p. 63.

9 Ibidem, p. 64

10 LAPORTA SAN MIGUEL, F.J. y otros, La Junta para ampliación de Estudios e Investigaciones Cientificas (1907-1936), Fundación Juan March, Madrid, 1974, ejemplar mecanografiado, 6 tomos.
} 
significa una relación entre unas y otras del $16,84 \%^{11}$ o sea, por expresarlas con palabras de este mismo estudio: «una tasa bastante alta que refuta las frecuentes acusaciones de anticlericalismo de que fue objeto el organismo» ${ }^{12}$. Este trabajo dice también que el número de solicitudes de pensión a lo largo de toda la vida de la Junta fue de $9.100^{13}$ y en otro lugar asegura que el número de concesiones superaron las $1.700^{14}$. Por tanto el porcentaje de concesiones es aproximadamente de un $18,6 \%$, algo superior al de los clérigos solicitantes, pero sin que el porcentaje de estos $(16,84)$ se desvíe mucho de la media.

No obstante a nosotros nos parecen más bien bajas las cifras dadas por Laporta y sus colaboradores, tanto en lo que se refiere a las solicitudes de pensión formuladas por clérigos (95) como, sobre todo, a las concesiones dadas por la Junta(16). Probablemente fueron más altas en uno y otro caso. Lo cierto es que solo en la letra «A», objeto de este estudio, se concedieron 7 pensiones a clérigos lo cual, a la vista de aquellos datos, quiere decir que únicamente serían 9 las pensiones concedidas a clérigos cuyo primer apellido comienza por cualquier otra letra del alfabeto que no sea la «A».

Por otro lado es significativo que, como veremos más adelante, fuesen 15 los clérigos cuyo primer apellido comienza con la letra «A» los que solicitaron pensión a la Junta y 7 las peticiones que ésta concediese, es decir, el 46,6\%. Es una cifra altísima y que se desvía mucho de los porcentajes anteriormente senalados. En cualquier caso es lo bastante significativa como para adelantar que no hubo discriminación de la Junta hacia los clérigos.

Los clérigos de la letra en estudio que solicitaron pensión fueron: José $\mathbf{M}^{2}$ Aguado, Francisco Aguilar Díaz, Fr. Basilio del Álamo, Maximino Luis Aldrey, Andrés Alonso Polo, Francisco Álvarez de Valenciano, Jesús Andrés García, Antonio Arenas Riera, Alfonso Andrés, Juan del Álamo y Álamo, Luis G. Alonso Getino, Gregorio Amor Mozo, Constante Amor Neveiro, Maximiliano Arboleya Martínez y Mariano Arigita y Lasa.

Como veremos a continuación a los ocho primeros no les fue concedida, a Alfonso Andrés se le concedió, pero por causas que no conocemos no la disfruto. Al resto les fue concedida pensión que disfrutaron. Además de todos estos, mencionaremos a Gregorio Arroyo Paniego que solicitó y le fue concedida una consideración de pensión y a Miguel Asín Palacios que nunca solicitó pensión de la Junta, pero que fue llamado por ella desde la creación del Cen-

11 Ibtdem, p. 37. En esta página se dice que el porcentaje es el 17,9\%; pero sin duda se trata de un error puesto que el porcentaje que se obtiene es el $16,84 \%$.

12 Ibldem, t. I, p. 278.

13 Ibidem, t. II, p. 72.

I4 Ibtdem, t. I, p. 240. 
tro de Estudios Históricos para dirigir una de las seis secciones con las que este centro comenz 6 su andadura.

Primero aparecerán por orden alfabético aquellos a los que no se les concedí y también el que no la disfrutó y el que solicitó y disfrutó la consideración de pensionado. Después, de nuevo por orden alfabético, haremos un estudio con detenimiento de aquellos que sí disfrutaron la pensión, para terminar con Miguel Asín Palacios, director de una de las secciones del Centro de Estudios Históricos y delegado español por nombramiento de la Junta en un congreso extranjero de su especialidad.

AGUADO, José $M^{2}$. Residía en Pajares de Adaja (Ávila) durante 1932. Había enseñado siete años Preceptiva e Historia Literaria en el colegio de Vergara (Guipúzcoa). Fue alumno de Menéndez ,Pidal y Américo Castro durante el curso 1923-1924 en la Universidad Central (de Madrid). Escribió varias obras literarias y colaboró habitualmente en la revista La Ciencia Tomista. Pidió pensión el 22-2-1932, para estudiar en la Universidad de Toulouse (Francia) el idioma provenzal y los poetas más relacionados con las literaturas españolas. No le fue concedida ${ }^{15}$.

AGUILAR DíAZ, Francisco. Había sido alumno del Pontificio Colegio Español de Roma. El 3-2-1936 solicitó pensión para estudiar en una universidad italiana. Le fue denegada la petición ${ }^{16}$.

ÁlAMO, Fr. Basilio del. Monje del monasterio de Santo Domingo de Silos, donde era profesor de Historia eclesiástica. No se le otorgó la solicitud de pensión presentada el 10-10-1920 para realizar estudios en la Escuela española de Roma para Arqueología e Historia ${ }^{17}$.

ALDREY, Maximino Luis. Pertenecía a la Orden franciscana. Durante su estancia en Palestina desde el año 1922 hasta el 1928 frecuentó las clases de asiriología y sumeriología en la «École Biblique et Archéologique Française de Saint-Étienne» de Jerusalén. También estudió tres años las lenguas árabe y siriaca con un monje maronita del Monte Líbano.

El 20 -10-1931 solicitó pensión para realizar estudios de asiriología y sumeriología por dos años en la Universidad de Berlín. Se le concedió la consideración de pensionado el 28-2-1933. No consta que la disfrutase ${ }^{18}$.

\footnotetext{
15 Archivo JAE, caja 1796.

$16 \mathrm{lbidem}$.

17 Ibidem, caja 1797.

18 lbidem, caja 1798.
} 
ALonso PoLo, Andrés. Nació en Pedrosillo de Alba (Salamanca) en 1876. Era doctor en Teología y Filosofía y catedrático de Lengua Griega en el colegio de Estudios Superiores de Calatrava. Pidió pensión para estudiar uno o dos años Filología Hispánica en Hispanoamérica o el griego moderno comparado con el clásico en Grecia. No se le concedió la ayuda solicitada ${ }^{19}$

ÁlvareZ de Valenciano, Francisco. Residía en Olloniego (Oviedo) cuando pidió pensión el 27-3-1923 para estudiar ciencias, idiomas y dialectos. No fue aceptada su solicitud ${ }^{20}$

ANDRES, Alfonso. Monje benedictino de Santo Domingo de Silos. Se le otorgó una pensión de nueve meses por Reales órdenes de 28-9-1916 y 19-11917 para investigar en la Escuela Española de Roma para Arqueología e Historia, documentos referentes a España contenidos en los Regesta Pontificios del siglo XVI, pero no hizo uso de la beca concedida ${ }^{21}$.

ANDRES GARCÍA, Jesús. Era catedrático de sociología en el Seminario Conciliar de Logroño en 1914, fecha en la que solicitó pensín de la JAE y le fue denegada ${ }^{22}$.

ARENAS RIERA, Antonio. Natural de Barcelona. Solicitó pensión en 1910 para completar sus estudios en Berlín. No fue admitida su propuesta ${ }^{23}$.

ARROYO PANIEGO, Gregorio. Fue Procurador general de la Orden benedictina y Superior de la residencia de Madrid. Se le concedió la consideración de pensionado por R.O. de 31-7-1919 para investigar durante uno año en Méjico acerca de «España y la cultura mejicana durante la época colonial». Según la Memoria de la JAE hizo uso de la ayuda otorgada ${ }^{24}$, aunque esto no conste claramente en la documentación del archivo de la $\mathrm{JAE}^{25}$.

Álamo Y Álamo, Juan del (Santo Domingo de Silos [Burgos] 13.VIII.1890 - Madrid 3.V.1970) historiador, fil6logo. Equiparado a pensionado (Francia, 1928). Pensionado (Francia, 1931-32, 1 año); (Francia, 1933, 10 meses) ${ }^{26}$.

\footnotetext{
19 Ibidem, caja 1799.

20 Ibrdem, caja 1801.

21 JAE, Memoria correspondiente a los años 1916 y 1917, Madrid, JAE, 1918, p. 20; Archivo JAE, caja 1801.

22 Archivo JAE, fichero.

23 Ibidem, caja 1803.

24 JAE, Memoria correspondiente a los años 1918 y 1919, Madrid, JAE, 1920, p. 73.

25 Archivo JAE, caja 1804.

26 Ibtdem, caja 1979. JAE, Memoria correspondiente a los ahos 1933-34, Madrid, JAE, 1935, pp. 23-24.
}

Hispania, del Mediterráneo al Atlántico Hispania Sacra 51 (1999) 
Inició sus estudios eclesiásticos en el monasterio benedictino de su villa natal y los termino en el Seminario de Burgos, donde fue ordenado presbítero en 1915. Posteriormente obtuvo el grado de bachiller en el Instituto de Soria y cursó la licenciatura de filosofía y letras, sección historia, en las Universidades de Oviedo y Zaragoza. Durante sus estancias en Madrid, Silos y Cogullada publicó algunos artículos sobre historia eclesiástica en distintas revistas. En el transcurso del año 1925 estuvo en Marsella como sacerdote auxiliar de la parroquia de Santa María del Monte. De 1926 a 1928 residió en París. Aquí ayudó como coadjutor en la parroquia de San Marcelo, frecuentó el Instituto de Estudios Hispánicos de la Universidad y dí́ clases de español en varios colegios.

Con la consideración de pensionado que le concedió la Junta el 6 de octubre de 1928 se trasladó a Marsella. En esta ciudad consultó los archivos departamentales «Des Boûches-du-Rhône», estudiando la influencia de la Abadía de San Víctor en la vida de la España medięval.

En 1931 presentó en Madrid su tesis doctoral titulada «Introducción a la colección diplomática de S. Salvador de Oña (822-1284)», que fue calificada con premio extraordinario. Ese año recibió de la Junta una pequeña subvención que aprovechó para examinar en la Biblioteca Nacional de París fondos procedentes de la Abadía de Silos. Asistió también, entonces, a las clases de paleografía y diplomática que impartían respectivamente los profesores Bouard y Prou en la «École des Chartes». De regreso a Madrid, el 23 de septiembre de 1932 ganó la cátedra de lengua francesa del Instituto de Orihuela, ciudad en la que residió varios meses.

En febrero de 1933 volvió de nuevo a Francia, pensionado por la Junta, para transcribir en la Biblioteca Nacional de París la parte inédita de los códices visigóticos españoles (siglos X y XI), de carácter hagiográfico, denominados «Vitae Sanctorum». Todos estos códices tienen gran valor por el volumen de datos históricos, hagiográficos, geográficos, lingüísticos, jurídicos, cronológicos y paleográficos que en ellos figuran. Durante su pensión, de diez meses, llevó a cabo la transcripción de dichos códices y redactó una introducción general con una reseña histórica de los mismos, desde su salida de Silos hasta su último paradero en la Biblioteca Nacional de París, tras la compra efectuada por Leopoldo Delisle en 1878.

En enero de 1934 fue nombrado catedrático del Instituto de Ciudad Real. Ocupo el cargo de director de este centro desde noviembre de 1935 hasta el 24 de septiembre de 1936, fecha en que fue declarado cesante por el Gobierno de la República. En el transcurso de la guerra civil permaneció oculto cerca de 30 meses para poder salvar su vida. Terminada la contienda española reanudó sus clases en el Instituto de Ciudad Real. Después se incorporó el 5 de marzo de 1942 al Instituto Beatriz Galindo de Madrid, y el 13 de octubre del mismo año 
al de San Isidro. A partir de entonces consagró su trabajo profesional a la lengua y a la literatura francesas, y publicó varios métodos y manuales para la enseñanza de este idioma que tuvieron gran aceptación. También publicó alguna obra sobre educación y sobre historia y algún artículo en la Revista de Archivos, Bibliotecas y Museos.

ALONSo GETINO, Luis G. (Lugueros [León] 12.XI.1877 - Madrid 9.VII.1946) historiador. Equiparado a pensionado (Cuba, México, Guatemala, San Salvador, Honduras, Nicaragua, Costa Rica, Panamá, Perú, Chile, Argentina, 1922). Pensionado (Francia, Bélgica e Inglaterra, 1932, 3 meses) ${ }^{27}$.

Después del año de noviciado en el convento de Padrón (La Coruña), profeś en la Orden de Predicadores el 14 de noviembre de 1893.

Había iniciado allí sus estudios de filosofía, que luego terminó en el convento de Corias (Oviedo). En 1896 comenzó la teología en el Estudio General de San Esteban de Salamanca, y en 1901 fue ordenado sacerdote. Inmediatamente después enseñó diversas materias (hermenéutica sagrada, historia eclesiástica, Iugares teológicos, etc... ) en el mismo Estudio General de San Esteban, hasta 1909. En este año se trasladó a Madrid, donde fundó la revista La Ciencia Tomista, que dirigiría desde entonces hasta 1912, año en el que fue elegido prior del convento de Oviedo. Al término de su cargo en 1916, volvió a asumir la dirección de La Ciencia Tomista, ejerciéndola hasta 1922. El mes de julio de este año fue elegido prior provincial de la provincia de España.

Tres meses después, la Junta para Ampliación de Estudios le otorgó la consideración de pensionado para que visitara las Repúblicas hispanoamericanas de Cuba, México, Guatemala, San Salvador, Honduras, Nicaragua, Costa Rica, Panamá, Perú, Chile y Argentina. Durante varios meses estudió en ellas el período colonial de sus respectivas universidades.

Fund6 en 1924 el boletín Memorandum y, al año siguiente, obtuvo por concurso público la plaza de cronista de la provincia de Salamanca. Antes de terminar su mandato de provincial en julio de 1926, participó con otros en la creación de la Asociación Francisco de Vitoria, de la que fue bibliotecario, así como editor de su Anuario.

De julio a octubre de 1932 fue pensionado por la Junta para Ampliación de Estudios con el fin de que realizase investigaciones sobre la actuación de los profesores españoles en París en el primer tercio del siglo XVI. Su estancia en el extranjero transcurrió principalmente en Francia y Bélgica; también realizó un corto viaje a Inglaterra. Visitó las más importantes bibliotecas de París, Londres, Bruselas, Lovaina, Amberes, Gante, Bayona y Oxford. Examinó los códices de

27 Ibfdem, caja 1799; JAE, Memoria correspondiente a los años 1922-23 y 1923-24, Madrid, JAE, 1925, p. 108; JAE, Memoria correspondiente a los afios 1931-32, Madrid, JAE, 1933, pp. 21-28.

Hispania, del Mediterráneo al Atlántico

Hispania Sacra 51 (1999) 
Durando de España (1330), Santiago de Cataluña (1356-1371), Domingo Alqueza (1400), Bernardo Ermegan (s. XIV), Gombau de Ulugía (s. XIV), Bernardo Oliver (S. XIV), Adolfo Vargas (s. XIV), Dionisio Murcia (s. XIV), Juan Ballester (s. XIV), Francisco Bacho (s. XIV), Bernardo Oller (s. XV), Francisco Martín (s. XV), Rodrigo Álvarez de Noreña (s. XV) Juan Andrés (s. XV) y Antonio de Ávila (s. XV). Pero su investigación se centró en el análisis y descripción de las obras de Juan de Celaya, Sancho Carranza de Miranda, Diego López de Zúñiga, Juan Martínez Siliceo, Pedro Ciruelo, Luis Coronel, Antonio Andres, Cipriano Benet, Gaspar Lax, Fernando de Encina, Antonio Núñez Coronel, Agustín Pérez Oliva, Jerónimo Pardo y Juan Oliver, así como de la II-II de CrocKaert publicada por el P. Vitoria (París, 1515), tomando como base el único ejemplar existente en el mundo (Bibl. Royal de Bruxelles, Ej. 24.768).

De nuevo en Madrid, continuó escribiendo temas históricos sobre su orden, restauró una comunidad de dominicos en la Basílica de Atocha y fundó la biblioteca Clásica Dominicana, de la que publicó dieciséis volúmenes. En octubre de 1935 fue nombrado superior de la casa-vicaría de Santo Domingo el Real y, pocos meses después, en marzo de 1936, hubo de desplazarse a Roma debido a la inclusión de su obra, Del gran número de los que se salvan y de la mitigación de las penas eternas en el Índice de libros prohibidos. El comienzo de la contienda civil, le obligó a permanecer en Francia varios meses. En octubre de 1936 pudo regresar a España y fijó la residencia en Toledo. Terminada la guerra volvió a Madrid, donde prosiguió su actividad como escritor y conferenciante hasta pocos días antes de su muerte.

Su producción bibliografica es enorme. Publico 55 obras entre las que se encuentran una traducción y dieciséis ediciones. También colaboró asiduamente en La Ciencia Tomista y Memorandum, revistas que él mismo fundo, y en el Anuario "Francisco de Vitoria», del que era editor, y escribió algún artículo en varias revistas madrileñas: Revista de las Españas, Revista IberoAmericana de Ciencias Eclesiásticas, Revista de Archivos, Bibliotecas y Museos, Revista de Ciencias Eclesiásticas y Escorial; en el Santísimo Rosario, de Vergara (Guipúzcoa); en el Anuario de Estudios Americanos, de Sevilla; y en Analecta Sacri Ordinis Fratrum Praedicatorum, de Roma.

Gran parte de los escritos del P. Alonso Getino versan sobre temas de la Orden de Predicadores a la que él perteneció. En sus artículos y obras estudió principalmente: la figura de Santo Domingo de Guzmán y el origen histórico de la devoción mariana del rosario, la personalidad del $P$. Francisco de Vitoria y el averroísmo teológico de Santo Tomás de Aquino, cuestión esta última sobre la que entabló una fuerte polémica con Asín Palacios. 
AMOR MOzo, Gregorio $(\Varangle \ldots ?-\Varangle \ldots ?)$ presbítero, sociólogo. Pensionado (Francia y Bélgica, 1911-12, 1 año). Pensionado en grupo (Francia y Bélgica, 1912,1 mes) ${ }^{28}$.

Siendo catedrático del Seminario de Palencia fundó en este centro, hacia 1900, un círculo de lectura y una biblioteca. El día 21 de diciembre de 1903 fue nombrado, previa oposición, canónigo doctoral de la catedral de la capital palentina. En esta ciudad impartió clases de filosofía en el seminario y desarrolló gran actividad como consiliario del Círculo Católico de Obreros. Durante estos años escribí a menudo sobre temas de carácter social, especialmente en la revista La Propaganda Católica. A partir de 1904 inició la publicación del periódico Obreros y Patronos, que trataba cuestiones obreras y agrarias de Castilla. El año 1906 accedió, por oposición nuevamente, a una canongía en Valladolid y a la cátedra de sociología del seminario de dicha ciudad. En varios pueblos de esas dos provincias dio conferencias sobre instrucción agraria, crédito agrícóla e instituciones de mutualidad y logró que se establecieran algunas Sociedades de Socorros Mutuos.

Desde julio de 1911 hasta finales de junio de 1912 estuvo pensionado en París, aunque pasó una temporada en Lovaina. Examinó la relación de la sociología con la filosofía de la historia, y asistió a varios cursos y conferencias en el Instituto de Francia, Instituto Católico de París, en la Sorbona y en la Escuela de Estudios Sociales. Terminada la pensión empezó a publicar una serie de artículos en La paz social y en la Revista del Clero español: «La doctrina de Comte», «Conceptos de la ley natural y libertad», «Las Leyes sociologicas», «El medio físico y la civilización» $\mathrm{y}$ «Estudio de geografía y sociología comparadas».

El 26 de junio de 1912 se hizo cargo de la dirección del siguiente grupo de obreros que ese mismo día habían llegado a París enviados por la Junta: Antonio Fernández Perdones, de Madrid; Valentín Fernández Cueto, de Bárcena de Pie de Concha (Santander); Francisco Barrachina Esteban, de Valencia: Abundio Marín Salenet, de Zaragoza; y Joaquín Palomer, de Barcelona. Tras casi un mes de pensión, regresaron a España el 22 de julio del año indicado. Comenzaron su trabajo en París, donde visitaron el Hotel Popular para hombres, la Unión Familiar, el Sindicato de Empleados del Comercio y de la Industria, la Unión de Trabajadores Libres, la Unión católica de empleados de ferrocarril, la Obra de los círculos católicos de obreros, la Asociación católica de la juventud francesa, la Unión popular católica, la Asociación fraternal de los empleados y obreros de los ferrocarriles franceses, la Confederación General del

28 Archivo JAE, caja 1801; JAE, Memoria correspondiente a los años 1910-11, Madrid, JAE, 1912, pp. 31-32; JAE, Memoria correspondiente a los años 1912-13, Madrid, JAE, 1914, p. 42. 
Trabajo, la Unión cooperativa de las sociedades francesas de consumo y la Bolsa del trabajo.

En Reims, el grupo estudió la Acción Popular, obra de propaganda que difundía ideas y métodos de acción social. Asimismo visitó la bodega Pommery, como ejemplo de fabricación y exportación a gran escala. También dedicó un día a la fábrica de tejidos de León Harmel, en Val-de-Bois, importante industria con amplia red de instituciones sociales. El grupo pasó después a Bélgica, donde visitó en Bruselas el Secretariado de las obras sociales, la Bolsa del trabajo, una cooperativa, el Círculo de estudios sociales, la Alianza nacional de las federaciones de mutualidades, la Obra de los obreros que emigran a Bruselas, las Obras de las clases medias; y en Gante, el Secretariado general de las uniones profesionales cristianas de Bélgica, el Secretariado de los obreros que emigran temporalmente a Francia, la Federación de las Mutualidades y Cajas de Retiro, una cooperativa, el Secretariado de las uniones profesionales, una escuela de hogar, etc... Los obreros conversaron en el citado país con dos eminentes sociólogos, el abate Vossen y el Padre Rutten; con el director general de Agricultura, M. de. Vuyst: y con el director de Industria y Comercio, M. Verhees. También vieron, en Bruselas, la Casa del Pueblo, el Secretariado de las obras femeninas, la Bolsa del trabajo femenino, el Feminismo cristiano de Bélgica y la Liga católica del sufragio femenino; en Amberes, el Hospital de los capellanes del trabajo, la Escuela profesional metalúrgica para el trabajo del diamante, una cooperativa y el Secretariado de las obras políticas; en Lovaina las Obras agrícolas y el Instituto del Sagrado Corazón y de la Inmaculada Concepción; y en Gante, el Vooruit.

El éxito del viaje se debió en gran parte al ministro de España, Alfonso Merry del Val. Los obreros de este grupo, a su regreso, publicaron en diferentes revistas católicas varios artículos sobre las instituciones visitadas y algunos impartieron conferencias sobre el particular. Además de en las ya citadas, Gregorio Amor colaboró en la revista Renovación Social y publicó dos libros sobre cuestiones sociales.

AMOR NEVEIRo, Constante (Santo Tomás de Ames (La Coruña) 29.IV.1862 - Santiago de Compostela (La Coruña) 30.V.1935) jurista. Pensionado (Italia, 1911, 4 meses y 15 días) ${ }^{29}$.

Cursó los estudios eclesiásticos en el Seminario Conciliar de Santiago (1870-1874), donde se gradú de bachiller y obtuvo la licenciatura y el doctorado en teología y derecho canónico. En la Universidad de dicha ciudad estudió también đerecho civil y canónico, licenciándose en 1896, y doctorándose

29 Archivo JAE, caja 1801, JAE, Memoria correspondiente a los afios 1910-11, Madrid, JAE, 1912 , p. 32 
en Madrid con la tesis Naturaleza y origen histórico del derecho de castigar, en 1900 .

Desde 1880 colaboró en varios periódicos importantes y en 1884 fue ordenado presbítero, con dispensa de edad. Obtuvo en 1886, previo concurso de oposición, el curato de San Cristóbal del Abanqueiro; en 1893 el de San Julián de Vastabales; y en 1896, el puesto de rector de San Félix de Solorío y Santa María Salomé en Santiago. Ostentó los cargos de provisor de la dí́cesis compostelana, párroco consultor del prelado, juez sinodal y censor de publicaciones. Fue también presidente, unas veces, de la sección de teología y, otras, de la de ciencias sociales del Ateneo León XIII de Santiago; consiliario del Círculo Católico de Obreros de la misma ciudad; presidente de la cofradía de presbíteros llamada Prima etc. Asimismo participó en diversos congresos de su especialidad celebrados en España y fue premiado en cuatro certámenes científicos.

Realizó una importante labor periodística de índole doctrinal y polémica, en contra del sistema parlamentario y la democracia y en pro del sistema orgánico sustancial a la manera de las antiguas Cortes de Castilla. Ejerció esta actividad sobre todo desde el diario compostelano El Lebredón. a cuya redacción perteneció entre1893 y 1895. En política fue hombre de ideas conservadoras, pero independiente.

Especializado en estudios sociales, fundamentalmente penalistas, intervino en numerosos congresos, como el «Económico Regional» organizado por la Sociedad Económica de Amigos del País en Santiago (1897), el «IV Congreso Católico Español» celebrado en la misma ciudad (julio 1902), el «II Congreso Penitenciario Español» de La Coruña (1914), el de la Asociación para el Progreso de las Ciencias de Oporto y el de la misma Asociación en Salamanca. En todos ellos ocupó la vicepresidencia de alguna reunión, y en el último citado, presentó tres memorias: «Noción de justicia: justicia objetiva y subjetiva» (Sección de Teología), «Las personas responsables de los delitos y faltas» (Sección de Ciencias Sociales), e «Invenciones y adelantos hechos por los españoles en el siglo XVI y principios del XVII en el terreno de las ciencias físicas» (Sección de Ciencias Físicas).

Fue pensionado por la Junta durante cuatro meses y medio en Italia a fin de perfeccionar sus conocimientos de derecho penal y sociología criminal. Desde febrero de 1911 y durante dos meses asistió en la Universidad de Roma a la clase del Pr. E. Ferri sobre derecho y procedimientos penales y a las de los profesores Sergi y Pigorini. A comienzos de abril vino a España para hacer oposiciones y regresó a Roma el 2 de mayo permaneciendo en Italia hasta julio. Durante este tiempo estuvo en Módena, Bolonia, Turín, Milán y Florencia, relacionándose con los profesores Alimena, Stoppato, P. Gemelli, Mayno y P. Bianchi. Al finalizar la pensión presentó a la Junta una memoria sobre «Las

Hispania, del Mediterráneo al Atlántico Hispania Sacra 51 (1999) 
causas psicológicas de los delitos» $y$, posteriormente, otra sobre «Las causas sociológicas de los delitos», y una tercera, titulada «Mi excursion a Italia». En Abril de 1913 la Junta acordó concederle el certificado de suficiencia.

Por sus obras y méritos fue nombrado, por unanimidad, académico correspondiente de la Real de Ciencias Morales y Políticas, cuando no había más que ocho en España. Su contribución al derecho penal fue importante. Entre los fines de la pena señalaba la restauración del orden perturbado por el delito, la expiación, la ejemplaridad y la corrección interior del penado. Defendió la pena de muerte, aunque no era partidario de aplicarla a los activistas anarquistas ni a los procesados por delitos puramente políticos.

Escribió 13 libros sobre legislación y jurisprudencia y publicó algún artículo en la Revista de Legislación y Jurisprudencia.

ARBOLEYA MARTINEZ, Maximiliano. (Pola de Laviana Asturia 9.10.1870 Meres [Asturias] 19.1.1951) presbítero, publicista y activista social. Pensionado (Italia y Bélgica, 1913-14, 3 meses) ${ }^{30}$.

Cursó la carrera eclesiástica en el Seminario conciliar de Oviedo, desde 1884 hasta 1893, fecha en la que se trasladó a Roma. En esta ciudad estudió en el Colegio Español; en la Universidad Gregoriana, donde obtuvo los títulos de bachiller en teología y en derecho canónico; y en el Colegio Pontificio del Apolinar, donde se graduó de bachiller y se licenció y doctoró en derecho civil y canónico.

Volvió a la capital asturiana en 1895, año en el que fué ordenado presbítero por su tío Martínez Vigil, obispo de la díccesis. En 1898 obtuvo por oposición la plaza de canónigo magistral de la catedral de Oviedo. Desde entonces colaboró en el periódico El Carbayón, que dirigió entre 1901 y 1912. Su preocupación por la cuestión social le llevó a propugnar la sustitución de los Círculos Católicos de Obreros por Uniones Profesionales que estuviesen constituidas y dirigidas ś́lo por obreros, con el asesoramiento de sacerdotes y juristas, y sin la mediatización de los patronos. Esta actitud le enfrentó al propio Marqués de Comillas y a ciertos sectores de la Compañía de Jesús.

La Junta le concedio una pensión de tres meses para estudiar en Italia y Bélgica la acción social católica y las organizaciones profesionales. Residió en estos dos países desde principios de noviembre de 1913 hasta comienzos de febrero de 1914. Viajó primero a Pisa, donde mantuvo conversaciones con el economista Toniolo. En Roma asistió a la cátedra de Mons. Potier, y estudió la historia, organización y funcionamiento de las Uniones Obreras Profesionales, la Federación de la Mutualidad, los Secretariados Obreros y la juventud católi-

30 Archivo JAE, caja 1803; JAE, Memoria correspondiente a los años 1914-15, Madrid, JAE, 1916, pp. 41-42. 
ca. Visitó también Bolonia, Bêrgamo, Milán, Bruselas, Gante, Malinas y otras ciudades, reuniendo en ellas amplia información social. Como fruto de su pensión, publicó en la Revista Eclesiástica, un artículo en el que exponía la obra social del obispo de Bérgamo; en la Revista del Clero Español, dos trabajos dedicados al Secretariado General de las Uniones Profesionales, fundado y dirigido en Gante por el P. Rutten; y en la Revista Social Hispano-Americana, un extenso estudio sobre las obras sociales de Bérgamo.

Tras su regreso a España, continuó trabajando por los sindicatos obreros que dirigía en Oviedo, y aplicó a éstos los conocimientos adquiridos en su viaje por Europa. A la Federación de Sindicatos Obreros Independientes le dotó de una Bolsa del Trabajo; y a la Federación Diocesana de Sindicatos Agrícolas, de una Sección de Compras. Asimismo organizó para ambas una Caja Central de Ahorros y Préstamos. También fundó entonces en aquella ciudad la «Casa del pueblo», donde desarrollaban sus actividades distintos grupos de promoción obrera: el Secretariado Obrero, la Federación Mutualista, la oficina de Documentación, etc...

Ante las acusaciones de sectarismo que hacían a la Junta elementos conservadores y derechistas, Arboleya la defendió, publicando dos artículos, el primero en $\mathrm{ABC}$ el 8 de marzo de 1914, y el segundo en El Debate el 18 del mismo mes. En ellos señalaba la imparcialidad de aquel organismo y valoraba positivamente el envío de los pensionados al extranjero por parte del mismo.

Fue miembro del Grupo de la Democracia Cristiana, que se constituyó en 1919. Pero tanto este partido como el sindicalismo profesional, se verían detenidos por la Dictadura de Primo de Rivera.

El año 1922 creó la Federación Asturiana Católico-Agraria, que alcanzó pujante vida y llegó a constar de una caja central, 72 sindicatos y gran número de cajas rurales.

En 1923 fue nombrado deán del Cabildo de la catedral de Oviedo. Entonces influyó en la realización de importantes obras en la iglesia catedralicia, como la total renovación de la techumbre. Durante la guerra civil se refugió en Vizcaya y, debido a ello, cuando esta provincia quedó en la llamada zona nacional, fue acusado de haber colaborado con socialistas y nacionalistas vascos. Desde 1939 residiría en Meres, alejado de toda actividad pública.

Ostentó numerosos cargos eclesiásticos: catedrático de teología del Seminario conciliar de Oviedo; fiscal general, examinador sinodal y juez prosinodal del obispado; secretario en 1899 de la Junta diocesana para el Congreso Católico de Burgos; vicepresidente y presidente de la Liga de Defensa Eclesiástica; secretario de la Junta organizadora de peregrinaciones a Lourdes (1901);

Hispania, del Mediterráneo al Atlántico Hispania Sacra 51 (1999) 
director de la Cofradía del Perpetuo Socorro; secretario de una de las secciones del Congreso Eucarístico Internacional celebrado en Madrid, etc...

Consciente de la importancia de los medios de comunicación, colaboró en periódicos y revistas de diferentes provincias españolas: $A B C, E l$ Universo, $E l$ Tiempo, Luz Canónica, Revista de Cuestiones Sociales, Nuestro Tiempo, Revista General de Legislación y Jurisprudencia, España y América, Revista Eclesiástica Iberoamericana, todos ellos de Madrid; Renovación Social y Asturias Agraria, publicaciones periódicas de Oviedo; Revista Social y Revista Quincenal, ambas de Barcelona; los diarios El Labaro, de Salamanca, y $E l$ Pueblo Vasco, de Bilbao; etc. Trabajó para que la prensa católica adquiriese carácter popular y lo consiguió en parte. Escribió además 41 obras y 9 folletos. Hombre de pensamiento liberal propugnó posturas de apertura y de progreso, especialmente en el campo social. Por eso fue combatido a menudo por las fuerzas más intransigentes y reaccionarias, padeciendo incluso una denuncia ante la Santa Sede. Le atacaron los socialistas, de un lado, y los patronos incomprensivos, de otro. Defensor y organizador del sindicalismo católico confesional, sin mezcla patronal alguna, su obra y su doctrina revisten gran importancia en la historia del catolicismo social español.

ARIGTTA Y LASA, Mariano (Corella [Navarra] 7.IX.1864 - San Miguel de Aralar [Navarra] 15.VII.1916) presbítero, historiador. Pensionado (España, 1911-12, 9 meses) ${ }^{31}$.

Siguí la carrera eclesiástica en los seminarios de Tarazona (1876-1886) y Pamplona (1886-1893). Hizo luego en Toledo la licenciatura y el doctorado en teología. Vinculado estrechamente a Pamplona, de cuya catedral fue nombrado beneficiado en 1889 y canónigo dos años después, tuvo a su cuidado los archivos del Ayuntamiento de Pamplona (1896), del Cabildo Catedralicio de la misma ciudad y de la Diputación de Navarra (1897).

En 1910 donó al Centro de Estudios Históricos el primer tomo de su Colección de documentos inéditos para la Historia de Navarra, al tiempo que solicitó de la Junta la publicación de un segundo volumen, sin que esto se llevara a efecto.

No obstante, este organismo le pensionó desde julio de 1911 hasta marzo de 1912. Durante este tiempo seleccionó una serie de documentos de carácter histórico que, procedentes de diversos archivos, se encontraban en la Delegación especial de Hacienda de Navarra.

Desde 1914 hasta su muerte desempeñó el cargo de chantre de la Catedral de Pamplona. Fue correspondiente de la Real Academia de la Historia y vocal

\footnotetext{
31 Archivo JAE, caja 1804.
} 
de la Comisión de Monumentos Históricos y Artísticos de Navarra, además de director del Boletín Eclesiástico de la diócesis.

Su obra escrita fue muy copiosa. Hombre sumamente trabajador y erudito, descubrió aspectos nuevos de la historia religiosa de Navarra. Publicó 16 libros y algunos artículos en el Boletín Oficial Eclesiástico del Obispado de Pamplona, en el Boletín de la Comisión Provincial de Monumentos Artísticos de Navarra y en la revista La Avalancha de Pamplona.

ASÍ́ PALACios, Miguel (Zaragoza 5.VII.1871 - San Sebastián 12.VIII.1944) arabista. Delegado en Congresos (Copenhague, 1908). Director de la Seccín «Investigación de las fuentes para la historia de la filosofía árabe española» del Centro de Estudios Históricos (Madrid, 1910-16, 5 años) y profesor agregado del Centro de Estudios Históricos (Madrid, 1935-36, 1 año) ${ }^{32}$.

Estudió bachillerato en Zaragoza, primero en el colegio de los escolapios y después en el del Salvador de los jesuitas. En esta misma ciudad curso filosofía y letras. Fue entonces cuando Asín conocí a Julián Ribera, a quien debió su vocación arabista. Ribera fue el creador de la atmósfera científica que respiró Asín y el iniciador en España de los estudios sobre las influencias mutuas de las culturas musulmana y cristiana. Maestro y discípulo, a quienes sólo separaban 13 años de edad, permanecerán desde entonces unidos por estrechos lazos de amistad. Asín se licencí́ en filosofía y letras por la Universidad de Zaragoza el año 1894 y se doctoró por la de Madrid en 1896 con la tesis Algazel: dogmática, estética y mística, publicada cinco años más tarde con un prólogo de Menéndez Pelayo.

Compaginó estos estudios con la carrera eclesiástica que cursó en el Seminario Conciliar de San Valero. Fue ordenado sacerdote en 1895 y obtuvo en 1897 el título de doctor en teología por la Universidad de Valencia.

Entre 1896-1902 desempeñó la cátedra de humanidades y de historia de la filosofía en el Seminario de Zaragoza y fue capellán de las monjas del Sagrado Corazón. Editó sus primeros trabajos en la Revista de Aragón (1900-1905), fundada por Julián Ribera; participó en el homenaje a Francisco Codera y preparó oposiciones a cátedra universitaria. En 1903 gana la de lengua arábiga de la Universidad de Madrid, vacante por la jubilación de Codera, con quien Asín se relacionará intensamente en los primeros años de su etapa madrileña. Codera y Vives (Ribera se encontraba aun en Zaragoza) le introdujeron en diversos

32 Ibidem, caja 1805; JAE, Memoria correspondiente a los años 1908 y 1909, Madrid, Tip. Hijos de M. Tello, 1910, p. 28; JAE, Memoria correspondiente a los años 1912-1913, Madrid, JAE, 1914, pp. 240-242; JAE, Memoria correspondiente a los años 1914-1915, Madrid, JAE, 1916, pp. 174-175; JAE, Memoria correspondiente a los años 1916-1917, Madrid, JAE, 1918, p. 35-36; JAE, Memoria correspondiente a los años 1910-11, Madrid, JAE, 1912, pp. 33, 34 y 143-147. 
centros intelectuales. Acudía a la tertulia de Menéndez Pelayo y a la de Gillermo J. de Osma, donde se relacionó y trabó amistad con Alejandro Pidal, Maura y el Duque de Alba. En los años posteriores conoció a Alfonso XIII al que le unió una simpatía cordialísima al ser nombrado Asín sumiller de cortina del Palacio Real y más tarde colaborador de la Junta Constructora de la Ciudad Universitaria de Madrid.

Ribera se trasladó a Madrid en 1905, y de nuevo juntos maestro y discípulo crearon Cultura Española (1906-9), efímera pero importante revista. Asín repartía su tiempo entre la cátedra universitaria, la asistencia a los centros culturales y la investigación. Sus progresos en esta actividad iban en aumento y le proporcionaban ya cierto renombre.

En 1905 y 1908 fue a los Congresos Internacionales de Orientalistas, celebrados en Argel y Copenhague respectivamente. Al primero le acompañó Codera, al segundo Ribera. A éste último asistió como delegado de la JAE, que le subvencionó los gastos de viaje y estancia en la capital danesa. A partir de estas salidas al extranjero comienza a colaborar con frecuencia en revistas de otros países y en homenajes a sabios europeos como los dedicados a Derembourg o Amari. También en esos años aprovechó una visita a Granada para catalogar los manuscritos árabes de la Abadía del Sacro Monte.

En 1910 empezó a trabajar, junto con otros muchos, en el recién creado Centro de Estudios Históricos, dependiente de la JAE. Dirigí en él la Sección «Investigación de las fuentes para la historia de la filosofía árabe española» desde su fundación hasta junio de 1916, momento en el que ésta dejó de funcionar por la dimisión de Asín. Su colaboración allí fue breve pero productiva. Varios libros vieron entonces la luz y algunos jóvenes investigadores, entre los que se encontraban Ángel González Palencia, Maximiliano Alarcón, Pedro Longás, etc. tuvieron la oportunidad de conocer un magisterio que ya no abandonarían.

La Junta requirió la colaboración de Asín en varias ocasiones posteriores, pero éste no aceptó de ella ningún nombramiento hasta el 3 de mayo de 1935, fecha en la que se incorporó de nuevo al Centro de Estudios Históricos como profesor agregado.

En 1914 ingresó en la Real Academia de Ciencias Morales y Políticas, en 1919 en la Real Academia Española y en 1924 en la Real Academia de la Historia. Así mismo era miembro del Patronato del Instituto de Valencia de D. Juan.

Su vida continuaba siendo metódica en aquel entonces: la Universidad, las tertulias, las Academias y la investigación. Los viajes al extranjero le estaban prohibidos por motivos de salud. Tan sólo en cuatro ocasiones había salido de nuestras fronteras. En Semana Santa iba junto a Ribera al huerto que éste poseía en Puebla Larga; en junio al Monasterio de El Escorial, donde estudiaba 
los manuscritos árabes allí existentes al mismo tiempo que formaba un distinguido plantel de arabistas agustinos, entre los que sobresalieron los padres Marata y Antuña; y en verano a San Sebastián.

Su obra fue muy fecunda entre 1920-30. El centro de su trabajo en este período fue el estudio compaginado de las dos figuras más importantes del Islam hispánico: Ibn Hazm de Córdoba e Inb Arabi de Murcia.

En 1932 (Ribera estaba ya jubilado en Puebla Larga donde moriría dos años más tarde) se crean las Escuelas de Estudios Árabes de Madrid y Granada. Asín es nombrado director de la primera, en la que funda y dirige al año siguiente la revista Al Andalus. En 1935 abandona su cátedra universitaria, para dedicarse exclusivamente a la investigación, y se incorpora al Centro de Estudios Históricos como profesor agregado.

La guerra civil le sorprendió en San Sebastián, donde permaneció hasta el final de la misma. En esta ciudad dio clases de latín en el Instituto de Segunda Enseñanza y continuó su labor investigadora gracias a las fotocopias de los manuscritos de Oxford y Berlín sobre las obras de Avempace, que desde aquellas ciudades le enviaba el Duque de Alba.

A finales de 1939 reanuda sus actividades en Madrid. Reorganiza la Escuela de Estudios Árabes, integrada ahora en el Instituto «Arias Montano» del Patronato «Menéndez Pelayo», dependiente del recién creado Consejo Superior de Investigaciones Científicas; vuelve a dar clases en la Universidad; continúa sus indagaciones como arabista; y acude sin cesar a las tres Reales Academias de las que formaba parte.

En el CSIC ocupó varios cargos que comenzó a desempeñar en 1939 o 1940: vicepresidente primero del Pleno del Consejo (30.12.1939); presidente de la Comisión ejecutiva del Patronato «Menéndez Pelayo» (25.11.1940); vocal del Pleno en representación de la Real Academia (10.2.1940); vocal del Ejecutivo (9.3.1940); vocal de la Comisión permanente (9.3.1940); presidente del Patronato «Menéndez Pelayo» (14.3.1940); y director del Instituto, «Benito Arias Montano» (16.5.1940). En 1941 se jubiló de su cátedra universitaria y en 1943 fue elegido director de la Real Academia de la Lengua. En agosto del año siguiente moriría en San Sebastián, donde acostumbraba a pasar sus vacaciones estivales.

Dejó tras sí una obra de excepcional valía intelectual y un importante número de discípulos entre los que destacan Emilio García Gŕmez, sucesor del maestro al frente de la Escuela de Estudios Árabes y de la revista Al Andalus. Era un gran traductor y poseía una sólida formación filosófica. En su obra destaca la claridad, la precisión y el orden. Tres fueron los temas que cultivó como arabista: los históricos, los filológicos y, fundamentalmente, los filosófi- 
co-teológicos. Entre éstos últimos resaltan los que abarcan el análisis de la espiritualidad islámica en sí misma, en sus fuentes cristianas y en su influencia sobre la cultura occidental. Dedicó gran parte de su actividad a la docencia, no sólo en la Universidad, la Junta para Ampliación de Estudios o el Consejo Superior de Investigaciones Científicas, sino también en su propia casa, contribuyendo así a la continuación de la Escuela Arabista.

Colaboró en las revistas y colecciones europeas y americanas más autorizadas y siguió atentamente la producción literaria extranjera de su especialidad. Prueba de ello son sus numerosas reseñas de obras de distintos países.

El prestigio internacional del que goz6 Asín se tradujo en su pertenencia a diversas academias y corporaciones extranjeras: la «Hispanic Society of America», la «Real Academia de Ciencias» de Amsterdam, la «Medieval Academy of America», el «Comité International d'Historie des Sciences», la «Royal Asiatic Society» de Londres, la «Société Asiatique» de París, la Academia Arabe de Damasco, la «Koninkliljke Akademie van Wetenschappen» de Amsterdam, etc.

Asín Palacios destaca como primera figura entre los arabistas españoles del siglo XX. En su ingente producción escrita cabe señalar de modo especial obras que llamaron la atención de los especialistas por su originalidad y fina intuición, como El averrotsmo teológico de Santo Tomás de Aquino, monografía que fue muy controvertida por los círculos tomistas y La escatologia musulmana en la Divina Comedia. En este libro demuestra que Dante conoció textos de la literatura árabe antes de hacer su obra cumbre, tesis que originó numerosas y acaloradas polémicas.

Entre libros, folletos discursos, prólogos y notas preliminares tiene publicadas alrededor de 68 obras, además de varios artículos fundamentalmente en Al-Andalus (Madrid-Granada) y en la Revista de Aragón (Zaragoza), aunque también en el Boletín de la Real Academia de la Historia, Boletín de la Real Academia Española, en Cultura Española (Madrid), Revue de l'Orient Chrétien (París), Revue des Sciences Philosophiques et Théologiques (París) y Maroc Catholique.

Esta pequeña muestra de clérigos pensionados por la JAE, tres historiadores, uno de ellos también filólogo, un sociólogo, un jurista y un publicista y activista social (a los que hemos añadido el arabista Asín Palacios, director de la sección de Filosofía Árabe del CEH) rompe el tópico de la discriminación lievada a cabo por la Junta con respecto a los hombres de Iglesia. Mientras que el porcentaje de concesión de pensiones, en general está cifrado aproximada- 
mente en un $18,6 \%$, el $46 \%$ de los clérigos cuyo primer apellido comienza por la letra «A» que solicitaron pensión, la obtuvieron. No parece por tanto cierto que los clérigos fuesen excluidos de los beneficios de la JAE.

Por otro lado, de los 15 clérigos en estudio que solicitaron pensión, 8, es decir más de la mitad, la solicitaron antes de 1920 ( 5 de ellas, el $62,5 \%$ fueron concedidas); 6 de ellos, el $40 \%$ del total la solicitaron antes de 1915 (4 de ellas, el 66,6\% fueron concedidas). Además el clérigo Miguel Asín Palacios fue llamado a dirigir una sección del Centro de Estudios Históricos en 1910, momento en el que este centro fue creado. Luego tampoco parece cierto que la Junta en sus primeros años tendiese más que en los posteriores a favorecer en las pensiones a los sectores más avanzados o que los clérigos en los primeros años se mostrasen remisos a solicitar dichas pensiones.

No obstante, como más arriba indicamos, quedan pendientes posteriores estudios que analicen en su totalidad las solicitudes de clérigos y las concesiones obtenidas; así como que analicen también, la proporción de institucionistas que obtenían pensión, si en uno u otro caso se desviaban de la media, si las distintas proporciones fueron más o menos altas en los primeros años de la Junta, etc. Pero he aquí esta pequeña muestra que ha de tenerse en cuenta. 